\title{
Use of complementary and alternative medicine among Polish cancer patients
}

\author{
Mirosława Puskulluoglu1', Barbara Uchańska², Krzysztof A. Tomaszewski ${ }^{3,4}$, Aneta L. Zygulska \\ Paulina Zielińska', Aleksandra Grela-Wojewoda ${ }^{1}$
}

\author{
${ }^{1}$ Maria Sklodowska-Curie National Research Institute of Oncology, Krakow Branch, Krakow, Poland \\ ${ }^{2}$ Department of Anesthesiology and Intensive Care, University Hospital in Krakow, Krakow, Poland \\ ${ }^{3}$ Faculty of Medicine and Health Sciences, Andrzej Frycz Modrzewski Krakow University, Krakow, Poland \\ ${ }^{4}$ Scanmed St. Raphael Hospital, Krakow, Poland \\ ${ }^{5}$ Department of Clinical Oncology, University Hospital, Krakow, Poland
}

Introduction. The aim of this prospective study was to estimate the perception and popularity of complementary and alternative medicine (CAM) subtypes and the reasons for usage among adult Polish cancer patients.

Material and methods. The validated questionnaire was conducted among 310 patients. $24.1 \%$ of the patients used CAM during their oncological treatment. Risk factors for CAM usage were: female gender, university degree and radical treatment. The most common reasons for CAM usage were: boosting the immune system (46.1\%), improving well-being/ counteracting the ill effects of cancer and its treatment (40.8\%). The average level of satisfaction with CAM was high ( $\geq 3 / 5$ on a Likert scale). Nearly half of the patients (46.6\%) admitted not informing their doctors about their CAM usage. Conclusions. The growing popularity and heterogeneity of CAM methods make it an important issue for patient-doctor relations in Poland and other Central European countries. The results of this study indicate what topics should be covered while introducing patient education programs.

Key words: cancer, complementary and alternative medicine, CAM, questionnaire, patients

\section{Introduction}

Over the last few decades, the treatment of cancer has improved considerably. However, patients are constantly turning to methods that are not part of routine procedures. Complementary and alternative medicine (CAM) is a huge group of practices varying from alternative medical systems through mind-body interventions, biologically-based therapies, manipulation and body-based methods to energy "therapies". According to the National Center for Complementary and Alternative Medicine, it is "a group of diverse medical and health care systems, practices, and products that are not generally considered part of conventional medicine" [1] (tab. I).

Results obtained in numerous countries show that the range of CAM usage by cancer patients varies between 14.8\% and $73.1 \%[2,3]$. These data were obtained before the COVID-19 era and may be even higher now as during this period access to standard diagnostic and treatment procedures was limited, although results from Germany show similar statistics to those from pre-COVID-19 times [3]. There is also a shortage of current information about the application of CAM in Poland

\section{How to cite:}

Puskulluoglu M, Uchańska B, Tomaszewski KA, Zygulska AL, Zielińska P, Grela-Wojewoda A. Use of complementary and alternative medicine among Polish cancer patients. NOWOTWORY J Oncol 2021; 71:274-281.

This article is available in open access under Creative Common Attribution-Non-Commercial-No Derivatives 4.0 International (CC BY-NC-ND 4.0) license, allowing to download articles and share them with others as long as they credit the authors and the publisher, but without permission to change them in any way or use them commercially. 
Table I. The definition of the term "complementary and alternative medicine" $[1,2]$

\begin{tabular}{|c|c|c|c|c|}
\hline \multicolumn{5}{|c|}{ Complementary and alternative medicine } \\
\hline \multicolumn{5}{|c|}{$\begin{array}{l}\text { "the use of unproven interventions by individuals in conjunction with, or in place of, traditional or conventional means of treatment of various diseases or } \\
\text { disease-related symptoms" }\end{array}$} \\
\hline \multicolumn{2}{|c|}{ Complementary therapies } & \multicolumn{3}{|c|}{ Alternative therapies } \\
\hline \multicolumn{2}{|c|}{$\begin{array}{l}\text { "refers to using a non-mainstream approach together } \\
\text { with conventional medicine" }\end{array}$} & \multicolumn{3}{|c|}{ "refers to using a non-mainstream approach in place of conventional medicine" } \\
\hline $\begin{array}{l}\text { manipulation } \\
\text { and body-based methods }\end{array}$ & movement therapies & mind-body interventions & $\begin{array}{l}\text { biologically based } \\
\text { therapies }\end{array}$ & alternative medical systems \\
\hline - massage & - yoga & - meditation & - herbs/herbal remedies & - traditional Chinese medicine \\
\hline - relaxation techniques & - pilates & - prayer & - dietary supplements & - ayurveda \\
\hline \multirow[t]{2}{*}{ - chiropractic } & & - supportive groups & - vitamins & \\
\hline & & & - special diets & \\
\hline
\end{tabular}

and Central or Eastern Europe. It is important to estimate the popularity and perception of CAM among cancer patients in order to increase the awareness among physicians.

The aim of this study was to estimate the general perception of Polish cancer patients regarding CAM, its popularity, its types, and the reasons for its application. This research was also conducted to check if the profile of patients using CAM in Poland is similar to other countries and if there is any correlation between medical or sociodemographic factors and the popularity of CAM.

To the best of our knowledge, our study has been the first concerning the usage of CAM in Central or Eastern Europe among the cancer patient population.

\section{Material and methods \\ Ethical approval}

The study was approved by Jagiellonian University Ethics Committee (Decision No. KBET/3/B/2012). The study was performed in accordance with the ethical standards laid down in the 1964 Helsinki Declaration and its later amendments. All patients gave their written, informed consent to participate in the study. No conflict of interest was declared.

\section{Building a tool}

The questionnaire development process is describes in table II $[4,5]$. We followed the European Organization for Research and Treatment of Cancer Quality of Life Group guidelines for questionnaire development with some changes concerning: single country cultural consistency and creating the initial questionnaire in Polish instead of English [4]. Data for the validation process were gathered between January 2012 and January 2013.

\section{Study group}

\section{Inclusion and exclusion criteria}

Patients' inclusion criteria were: adult age (>18 years) and primary diagnosis confirmed by histopathological examination. There was no restriction as to the type of neoplastic disease or treatment type or intention. The exclusion criteria were: lack of informed consent to complete the questionnaire or refusal regarding accessing medical records.

\section{Data gathering}

The validated survey was conducted as a personal interview among patients between February 2013 and January 2016, with both men and women, at the Department of Clinical Oncology, University Hospital in Krakow. The inpatients of the Oncological Ward and outpatients from the Ambulatory Chemotherapy Clinic were recruited. Interviewers assured them about confidentiality before the interview started. In order to avoid concealment of information by the patients in the presence of their physicians, the interviewers were not involved in patients' treatment. Patients were instructed on how to complete the questionnaire and were allowed to ask questions whenever any uncertainties arose. After completing questions about the sociodemographic data, the patients were asked if they had used CAM. All patients were asked a question about their perception of what CAM is and if it is approved by conventional medicine. If patients admitted using CAM, they were asked follow up questions. The whole procedure lasted 10-25 minutes, depending on whether the patient used CAM or not.

Data gathered from the questionnaires were supplemented by patients' clinical records. Information acquired from patients' histories included questions about:

- type/intention of treatment (radical vs. palliative),

- current treatment (chemotherapy vs. radiotherapy vs. radiochemotherapy vs. hormonal therapy),

- history of previous oncological treatment (yes/ what type of treatment vs. no),

- date of diagnosis.

Table III shows the sociodemographic and medical data for 310 patients who completed the questionnaire.

\section{Statistical analysis}

Statistical analysis was performed with the use of Statistica 10.0 PL (Statsoft). Elements of descriptive statistics 
Table II. Actions taken to compile the questionnaire $[4,5]$

\begin{tabular}{|c|c|c|}
\hline Phases & Action & Description \\
\hline \multirow[t]{3}{*}{$\begin{array}{l}\text { Phase } 1 . \\
\text { Generation of } \\
\text { issues }\end{array}$} & searching databases & $\begin{array}{l}\text { - Medline (1993-January 2012), Scopus and Up-To-Date databases were screened for all studies } \\
\text { published in English concerning the use of CAM among adult oncological patients in Europe } \\
\text { - the following keywords were used according to Boolean logic rules: complementary and alternative } \\
\text { medicine, alternative medicine, alternative therapies, CAM, cancer, complementary therapies, Poland, } \\
\text { neoplasm, oncology, patients, survey, questionnaire } \\
\text { - the search strategy was developed specifically for each database } \\
\text { - the information was obtained initially from abstracts and then further complete papers }\end{array}$ \\
\hline & $\begin{array}{l}\text { interviewing the } \\
\text { patients }\end{array}$ & $\begin{array}{l}\text { - the interviews with patients ( } n=20 \text {; age range } 18 \text { to } 72 \text { years; } 10 \text { females and } 10 \text { males) were } \\
\text { performed } \\
\text { the patients were asked to describe their experience concerning CAM and were permitted to } \\
\text { provide information freely } \\
\text { - the procedure was stopped when no new issue arose }\end{array}$ \\
\hline & \multicolumn{2}{|c|}{$\begin{array}{l}\text { - discussing among health-care professionalsA list of } 33 \text { issues was generated and discussed among the authors of this study } \\
\text { and a group of six other health-care professionals (two nurses, two medical students and two oncologists) } \\
\text { - all assessed the relevance of each issue on the Likert scale ( } 1 \text { - not relevant at all, } 5 \text { - very relevant) and chose } 15 \text { issues for } \\
\text { further consideration } \\
\text { - the issue was selected if it achieved a mean score of } 3.5 \text { on the Likert scale and at least one-third of respondents prioritized } \\
\text { the issue } \\
\text { - finally, one overlapping issue was deleted }\end{array}$} \\
\hline \multirow{2}{*}{$\begin{array}{l}\text { Phase } 2 . \\
\text { Building } \\
\text { a provisional } \\
\text { questionnaire }\end{array}$} & $\begin{array}{l}\text { generating a list of } \\
\text { questions }\end{array}$ & $\begin{array}{l}\text { - the chosen issues were used to build the items for the questionnaire } \\
\text { CAM comprisional bersion consisted of } 21 \text { questions: eight about sociodemographic data and } 13 \text { about } \\
\text { CAM team }\end{array}$ \\
\hline & $\begin{array}{l}\text { - } \text { review by an expert } \\
\text { - review by an indepen }\end{array}$ & dent expert was performed \\
\hline \multirow{2}{*}{$\begin{array}{l}\text { Phase } 3 . \\
\text { Testing the } \\
\text { provisional } \\
\text { questionnaire }\end{array}$} & $\begin{array}{l}\text { assessment by health- } \\
\text { care professionals }\end{array}$ & \multirow{2}{*}{$\begin{array}{l}\text { - health-care professionals and patients found the } \\
\text { questions easy to understand and acceptable } \\
\text { confusing, upsetting or intrusive questions and } \\
\text { issues were corrected (according to suggestions) } \\
\text { after discussion between co-authors. E.g. } \\
\text { question about earnings was deleted to avoid } \\
\text { sensitive issues not directly pertaining to the } \\
\text { study's aim }\end{array}$} \\
\hline & $\begin{array}{l}\text { testing on a group of } \\
\text { patients }\end{array}$ & \\
\hline \multirow[t]{2}{*}{$\begin{array}{l}\text { Phase } 4 . \\
\text { Questionnaire } \\
\text { field-testing }\end{array}$} & $\begin{array}{l}\text { field-testing on a group } \\
\text { of patients }\end{array}$ & $\begin{array}{l}\text { - the final questionnaire developed for this study consisted of } 19 \text { items } \\
\text { - questions were mostly closed-ended with an open answer category after a list of possible answers } \\
\text { - questions were divided into three parts: sociodemographic data (six questions), usage and } \\
\text { perception of the CAM term (two questions), and questions about CAM usage - only for patients } \\
\text { - the main issues and most commonly used methods of CAM were specified. The number of } \\
\text { respondents used for field-testing was } 96 \text { (age range } 31 \text { to } 88 \text { years; } 55 \text { females and } 41 \text { males) } \\
\text { - results for test-retest reliability with an assessment } 2 \text { weeks after the baseline by using interclass } \\
\text { correlations showed a correlation from } 0.8 \text { to } 0.92, \text { which is considered excellent } \\
\text { - in terms of construct validity, Cronbach's alpha coefficient for the final questionnaire was } 0.77 \text {. This } \\
\text { value was considered acceptable }\end{array}$ \\
\hline & $\begin{array}{l}\text { final review of the } \\
\text { questionnaire }\end{array}$ & - the questionnaire was accepted by the research team \\
\hline
\end{tabular}

were applied (mean, standard deviation, percentage distribution). The Student's t-test was used when comparing quantitative variables and the Mann-Whitney $U$ test was applied in the absence of normal distribution of factors. The results of the univariate logistic regression were presented as odds ratios (OR) and 95\% confidence intervals (95\% Cl). P-values of less than 0.05 were considered to indicate statistical significance.

\section{Results}

Over $24.1 \%$ of all patients used CAM during their oncological treatment. The mean age was 58.1 years (+/-11.7SD). CAM users were more often women (OR=1.84; 95\% Cl: 1.07-3.13; $\mathrm{p}=0.025)$ and had a university education $(\mathrm{OR}=2.05 ; 95 \% \mathrm{Cl}$ : 1.18-3.57; $p=0.0107$. Between CAM users and non-users, there were no differences as regards duration of the oncological treatment, the place of residence, marital status or age ( $p>0.05)$. Patients during radical treatment tended to use more CAM than palliative patients $(\mathrm{OR}=1.81 ; 95 \% \mathrm{Cl}: 1.07-3.07 ; \mathrm{p}=0.0277)$. Patients with breast cancer used CAM more often than patients with other types of malignancies (OR $=2.67 ; 95 \% \mathrm{Cl}: 1.38-5.16 ; \mathrm{p}=0.0036)$.

Polish society is homogeneous - all patients from this study were Polish citizens and Caucasian. Regardless of whether they were CAM users or non-users, all patients were asked a question about their definition of CAM. Table IV shows what their comprehension of the CAM term was. The higher the education level of patients (secondary and university education) the better their knowledge of CAM ( $p<0.0001)$. The term "Other" in table IV means patients' own comments related to 
Table III. Sociodemographic and medical information about respondents

\begin{tabular}{|c|c|c|c|c|c|c|c|}
\hline & & \multicolumn{2}{|c|}{ All participants } & \multicolumn{2}{|c|}{ CAM users } & \multicolumn{2}{|c|}{ Non-users } \\
\hline & & No. & $\%$ & No. & $\begin{array}{c}\% \text { of all } \\
\text { participants }\end{array}$ & No. & $\begin{array}{c}\% \text { of all } \\
\text { participants }\end{array}$ \\
\hline \multirow[t]{2}{*}{$\operatorname{sex}$} & women & 161 & 51.9 & 48 & 15.5 & 113 & 36.5 \\
\hline & men & 149 & 48.1 & 28 & 9.0 & 121 & 39.0 \\
\hline age (years) & & 58.1 & & 56.2 & & 58.7 & \\
\hline \multirow[t]{4}{*}{ marital status } & single & 23 & 7.4 & 7 & 30.4 & 16 & 69.6 \\
\hline & married & 240 & 77.4 & 56 & 23.3 & 184 & 76.7 \\
\hline & widowed & 34 & 11.0 & 11 & 32.4 & 23 & 67.6 \\
\hline & divorced & 12 & 3.9 & 2 & 16.7 & 10 & 83.3 \\
\hline \multirow[t]{4}{*}{ place of living } & rural area & 117 & 37.7 & 31 & 26.5 & 86 & 73.5 \\
\hline & town/city of $<20000$ inhabitants & 25 & 8.1 & 6 & 24.0 & 19 & 76.0 \\
\hline & town/city of $20000-150000$ inhabitants & 35 & 11.3 & 10 & 28.6 & 25 & 71.4 \\
\hline & town/city of $>150000$ inhabitants & 133 & 42.9 & 29 & 21.8 & 104 & 78.2 \\
\hline \multirow[t]{4}{*}{ education } & elementary & 29 & 9.4 & 7 & 2.3 & 22 & 7.1 \\
\hline & vocational & 84 & 27.1 & 13 & 4.2 & 71 & 22.9 \\
\hline & secondary & 113 & 36.5 & 26 & 8.4 & 87 & 28.1 \\
\hline & university & 84 & 27.1 & 30 & 9.7 & 54 & 17.4 \\
\hline \multirow{2}{*}{$\begin{array}{l}\text { intention of } \\
\text { treatment }\end{array}$} & radical & 110 & 35.5 & 35 & 11.3 & 75 & 24.2 \\
\hline & palliative & 200 & 64.5 & 41 & 13.2 & 159 & 51.3 \\
\hline \multirow{4}{*}{$\begin{array}{l}\text { type of current } \\
\text { treatment }\end{array}$} & chemotherapy & 253 & 81.6 & 58 & 18.7 & 195 & 62.9 \\
\hline & chemoradiotherapy & 40 & 12.9 & 13 & 4.2 & 27 & 8.7 \\
\hline & radiotherapy & 3 & 1.0 & 2 & 0.6 & 1 & 0.3 \\
\hline & hormonal therapy & 13 & 4.2 & 3 & 1.0 & 10 & 3.2 \\
\hline \multirow{5}{*}{$\begin{array}{l}\text { type of } \\
\text { treatment used } \\
\text { in the past } \\
\text { (more than one } \\
\text { is possible) }\end{array}$} & chemotherapy & 147 & 47.4 & 40 & 12.9 & 107 & 34.5 \\
\hline & radiotherapy & 82 & 26.5 & 21 & 6.8 & 61 & 19.7 \\
\hline & surgery & 237 & 76.5 & 64 & 20.6 & 173 & 55.8 \\
\hline & other & 16 & 5.2 & 6 & 1.9 & 10 & 3.2 \\
\hline & no previous treatment & 22 & 7.1 & 2 & 0.6 & 20 & 6.5 \\
\hline \multirow{2}{*}{$\begin{array}{l}\text { place of } \\
\text { treatment }\end{array}$} & inpatient ward & 227 & 73.2 & 54 & 17.4 & 173 & 55.8 \\
\hline & outpatient clinic & 83 & 26.8 & 22 & 7.1 & 61 & 19.8 \\
\hline \multirow[t]{9}{*}{ type of cancer } & colorectal cancer & 59 & 19.0 & 23 & 30.3 & 78 & 33.3 \\
\hline & stomach cancer & 59 & 19.0 & 10 & 13.2 & 49 & 20.9 \\
\hline & breast cancer & 45 & 14.5 & 19 & 25.0 & 26 & 11.1 \\
\hline & lung cancer & 17 & 5.5 & 1 & 1.3 & 16 & 6.8 \\
\hline & head and neck cancer & 13 & 4.2 & 4 & 5.3 & 9 & 3.8 \\
\hline & pancreatic cancer & 9 & 2.9 & 1 & 1.3 & 8 & 3.4 \\
\hline & ovarian cancer & 9 & 2.9 & 3 & 3.9 & 6 & 2.6 \\
\hline & testicular cancer & 7 & 2.3 & 2 & 2.6 & 5 & 2.1 \\
\hline & others & 51 & 16.5 & 20 & 6.5 & 53 & 17.1 \\
\hline
\end{tabular}


Table IV. Patients' perception of the CAM term

\begin{tabular}{|c|c|c|c|c|c|c|c|}
\hline & & \multicolumn{2}{|c|}{ All participants } & \multicolumn{2}{|c|}{ CAM users } & \multicolumn{2}{|c|}{ Non-users } \\
\hline & & No. & $\%$ & No. & $\%$ & No. & $\%$ \\
\hline \multirow{6}{*}{$\begin{array}{l}\text { What, in your } \\
\text { opinion, does the } \\
\text { term "complementary } \\
\text { and alternative } \\
\text { medicine" mean? }\end{array}$} & $\begin{array}{l}\text { they are methods that are moderately approved by } \\
\text { conventional medicine (CM) }\end{array}$ & 58 & 18.7 & 20 & 6.5 & 38 & 12.3 \\
\hline & they are salutary methods unapproved by $\mathrm{CM}$ & 39 & 12.6 & 11 & 0.0 & 28 & 0.1 \\
\hline & $\begin{array}{l}\text { they are methods that could be used instead of } \\
\text { the CM }\end{array}$ & 4 & 1.3 & 2 & 0.0 & 2 & 0.0 \\
\hline & they are methods that could be used alongside CM & 109 & 35.2 & 39 & 0.1 & 70 & 0.2 \\
\hline & I do not have any opinion & 101 & 32.6 & 14 & 0.0 & 87 & 0.3 \\
\hline & other & 70 & 22.6 & 10 & 0.0 & 60 & 0.2 \\
\hline
\end{tabular}

decisions about the usage of CAM, like: "My family and friends encouraged me to use it, and I trust them; I think that CAM is safe for my health; I wanted to try everything possible; I do not trust CAM or I think CAM is a mind therapy, not body therapy".

Table $V$ presents the prevalence of using particular CAM methods. Most patients had more trust in conventional medicine (CM) (67.1\%), but there was also a group of CAM users (17.1\%) who trusted both CAM and CM the same way. Only 2.6\% (2 responders) trusted CAM more. The most commonly mentioned reason for using CAM was boosting the immune system (46.1\%). Other popular arguments were: improving well-being/ counteracting the ill effects of cancer and its treatment (40.8\%); improving the prognosis (38.2\%) and increasing the chance of recovery (28.9\%). The most common source of information about CAM was family and friends (57.9\%), over $34.2 \%$ of CAM users employed some CAM methods before their oncological treatment. The amount of money spent each month on CAM was lower than 50 PLN (around 13 USD) for

Table V. Prevalence of CAM usage

\begin{tabular}{|c|c|c|c|}
\hline \multirow[t]{2}{*}{ Method } & & \multicolumn{2}{|c|}{ CAM users } \\
\hline & & No. & $\%$ \\
\hline \multirow[t]{2}{*}{ manipulation and body-based methods } & massage & 3 & 3.9 \\
\hline & relaxation techniques & 2 & 2.6 \\
\hline movement therapies & yoga & 3 & 3.9 \\
\hline \multirow[t]{2}{*}{ mind-body interventions } & prayer & 24 & 31.6 \\
\hline & psychotherapy/ support groups & 6 & 7.9 \\
\hline \multirow[t]{7}{*}{ biologically based therapies } & dietary supplements & 31 & 40.8 \\
\hline & herbal medicine & 20 & 26.3 \\
\hline & special diet/modification of diet & 17 & 22.4 \\
\hline & apitherapy & 8 & 10.5 \\
\hline & amygdalin & 4 & 5.3 \\
\hline & capsaicin & 4 & 5.3 \\
\hline & aromatherapy & 1 & 1.3 \\
\hline \multirow[t]{5}{*}{ alternative medical systems } & $\begin{array}{l}\text { quackery/ } \\
\text { bioenergotherapy }\end{array}$ & 7 & 9.2 \\
\hline & homeopathy & 5 & 6.6 \\
\hline & acupuncture & 0 & 0 \\
\hline & Ashkar method & 0 & 0 \\
\hline & folk/traditional medicine & 0 & 0 \\
\hline other methods not listed above & & 20 & 26.3 \\
\hline
\end{tabular}


$27.6 \%$ of respondents: $50-100$ PLN for $25.0 \%$. About $17.1 \%$ of CAM users spent 100-200 PLN monthly, 6.6\% - 200-500 PLN and $7.9 \%$ more than 500 PLN. The most popular treatments mentioned by respondents were:

- alkylglycerol (Ecomer, containing shark liver oil) (6.7\% of CAM users),

- $\quad$ specially prepared juices from vegetables or fruit (6.7\%),

- vitamin $B_{17}$ - amygdalin (5.3\%),

- shark cartilage (5.3\%),

- $\quad$ noni juices (Morinda citrifolia) (5.3\%),

- extract from shiitake mushroom (Lentinula edodes) (4\%),

- extract from Polyporus betulinus nigricans (4\%),

- elements from Betula pendula (2.7\%),

- Graviola Immune (2.7\%),

- $\quad$ ayurweda (1.3\%) and pilates (1.3\%).

\section{Discussion}

\section{CAM usage - the profile of users and potential reasons for CAM usage}

Numerous researchers prove that CAM usage among cancer patients is higher than in the general population, but similar to patients with chronic diseases. Indeed, a recently published study regarding Polish patients with epilepsy showed similar percentages of CAM users in comparison to our population [6].

In this research, the profile of CAM users is the same as in many other research studies - patients with cancer using CAM tended to be female with higher education levels and were suffering from breast cancer. Better educated patients are probably more aware of their health status and show more interest in the process of their illness and treatment. CAM usage is connected with higher educational levels; in Israel, however, dietary supplement usage is more popular among people who are less formally educated. CAM can be seen as an active way to manage the disease, with some data suggesting that the intention of patients using CAM was to have a positive influence on their disease [7-10]. In this study, better educated patients seemed to have more ideas and reflections about CAM and they were probably more involved in the treatment of their disease. $4.5 \%$ of CAM users, in comparison to almost one third of non-users, did not have their own opinion about what CAM was. In Poland, the use of CAM was mainly affected by the influence of family and friends, while in the United Kingdom (UK), the Internet played a main role [11].

Alternative methods were nearly fifteen times more popular among Polish patients than complementary ones, while in other studies this disparity is smaller - alternative methods are only three times more popular [12]. An explanation for this might be the different motivations for choosing CAM. In this research, the most popular reason for using CAM was"boosting the immune system" and diet supplements seem to be the most suitable and accessible way of achieving this. Huebner et al. (Germany) indicated the importance of "the reduction of side effects" and a "desire to become active" as equally impor- tant, while Molassiotis et al. and other European researchers reported "increasing the body's ability to fight cancer" as the most popular reason; complementary methods may more effectively fulfill these demands $[13,14]$. Other reasons for the use of CAM by Polish patients were generally similar to those from other studies.

In Poland, patients during radical treatment tended to use CAM nearly twice as often as during palliative treatment, while other papers suggested that palliative patients, who have a poorer quality of life, are usually expected to use CAM more often. According to Eliott et al., palliative patients might be more depressive and hopeless and some of them might fail to continue to use CAM due to different practical and financial difficulties $[15,16]$. Complementary methods like relaxation or psychotherapy might be especially favorable for palliative patients. However, in Poland there is little general awareness about these methods. During palliative oncological treatment, the spiritual needs of patients and the various problems associated with the end of life should not be omitted or unnoticed. Unfortunately, in Poland the palliative treatment financed by the National Health Fund (NFZ) does not satisfy these demands. Moreover, overall psychological care in oncological and palliative departments is insufficient [17].

\section{CAM methods used}

Poland is a mainly Catholic country: $91.4 \%$ of the total population (2018, http://stat.gov.pl/) belong to the Latin Church of the Roman Catholic Church. 24\% of our participants claimed that they were praying for a cure. In this research, prayer was the second most common CAM among cancer patients, which is similar or less frequent to the outcomes from North Africa or Asia, while in Western Europe other methods were usually more popular [9, 18-20].

The profile of the method used in Poland is halfway between the profile from Western Europe or the USA and Asia. In Poland, like in Western countries and the USA, the most popular methods were mainly various diet supplements (tab. V) [8, 9]. Diet supplements - regardless of their effectiveness - are the simplest methods that can be applied. They do not usually require major changes in lifestyle or involve much time, attention or effort.

In Poland, methods like mind and body and relaxation techniques or acupuncture are still not very popular. In other European countries, relaxation is used by up to $32.4 \%$, acupuncture up to $13 \%$ and spiritual methods up to $20.0 \%$, while in our research it is only $7.8 \%$ for manipulation and body-based methods (also including relaxation), 3.9\% for movement therapies and $0 \%$ for acupuncture (tab. V).

A systematic review from the USA names exercises, acupuncture and meditation, yoga, massage and music therapy among the most frequently mentioned on comprehensive cancer center websites. They are offered to cancer patients as commonly as dietary supplements and even more commonly than herbs [21-22]. According to Scott et al., in the UK, where 
the average income is higher than in Poland, the most popular methods among cancer patients are relaxation, meditation and medicinal teas [12]. In Polish society these interventions are probably still regarded as "exclusive" and accessible only to younger people in bigger cities with higher incomes. In this study, participants were not asked about their income to avoid tactlessness, nevertheless the mean value of a salary in Poland in the first half of 2019 was 4951 PLN (1293 USD) (http://stat. gov.pl). More expensive methods (like acupuncture or massage) are unaffordable for many patients in Poland.

Moreover, in Poland and other countries from the Eastern Block (the former communist states of Central and Eastern Europe), common access to some methods, techniques and innovations was restricted for many years. 30 years ago this isolation ended, and the difficult and still ongoing reform of the health care sector began. It may still take many more years to overcome the challenges faced [23]. The mean age of this study population was 58.1 years which might suggest that many of the respondents might not be very familiar with the benefits of complementary therapies due to their age. Maybe the proportion of CAM types used will change over the coming decades. The last important factor is the fact that people living in smaller Polish cities or rural areas have limited access to some practices requiring professional staff (like yoga, pilates or support groups).

\section{Safety and patient-doctor communication issues}

7.9\% of our respondents claimed that using CAM delayed presenting oneself to a physician or oncologist with disturbing symptoms. This percentage is much lower than for the Asian population. A recently published retrospective study regarding a huge population (almost 2000 000) of cancer patients concluded that CAM usage was associated with refusal of standard treatment options and a higher risk of death. Earlier, Han et al. proved that CAM used as primary treatment for breast cancer increased the risk of progression, recurrence and death, however a study by Neuhouser et al. did not confirm this. Nevertheless, the risk of drug interactions when some of CAM methods are applied, in addition to standard oncological treatment, or even higher a risk of infections in some cases cannot be neglected [20, 24-27].

In our study, almost half the patients (46.57\%) admitted not informing their doctors about CAM usage and this matches the results of the review by Davis et al. regarding the number of patients who do not disclose CAM usage (20-70\%) [28]. Our patients point to their doctor's lack of inquiry as to the main reason for nondisclosure, and this was also demonstrated by other studies. It seems that patients lack the proper conversations about supportive methods for their oncological treatment. Other studies reported similar results about patients'fear of being judged by clinicians when sharing such information and their desire to be actively involved in their treatment [29-30].

\section{Limitations of the study}

The study has certain limitations, one of the biggest being the inequality of the groups - there were almost twice as many palliative patients involved than radical and more inward patients than outward. The survey did not investigate the usage of vitamin C infusions and this method was explored together with other methods as "dietary supplements". Regarding the growing popularity of vitamin C infusions, this topic should be covered separately $[10,31]$. An important influence on the proportion of women and men using CAM in our study was women with breast cancer - they accounted for $14.5 \%$ of all patients, but as many as $25.0 \%$ of all CAM users. Moreover, the response rate was not measured and the patients who did not give their consent to complete the questionnaire were not asked about their reason for refusal. The questionnaire needs a cross-cultural adaptation and a proper English translation in order to be used in other studies.

\section{Conclusions}

The study showed the differences between the USA,Western European and post-communist countries in terms of CAM usage in cancer patients. The profile of a Central European CAM user is also different from their Asian equivalent. Looking at the updated data from other regions, it can be assumed that Poland will also experience a shift in prevalence or types of CAM being commonly used.

The growing popularity and heterogeneity of CAM methods make it an important issue for patient-doctor relations in Poland and other Central European countries. Oncologists and general practitioners in our region should start talking about CAM with their cancer patients. The results of this study indicate what topics should be covered while introducing patient education programs in Poland.

\section{Acknowledgements}

The authors would like to thank Ms. Joanna Gołąb for editing the English version of the article.

\section{Conflict of interest: none declared}

\author{
Mirosława Puskulluoglu \\ Maria Sklodowska-Curie National Research Institute of Oncology \\ Krakow Branch \\ ul. Garncarska 11 \\ 33-332 Kraków, Poland \\ e-mail:mira.puskulluoglu@gmail.com
}

Received: 12 Jul 2021

Accepted: 20 Aug 2021

\section{References}

1. Complementary, Alternative, or Integrative Health: What's In a Name? NCCAM. https://nccih.nih.gov/health/integrative-health (3.07.2021).

2. Jones E, Nissen L, McCarthy A, et al. Exploring the Use of Complementary and Alternative Medicine in Cancer Patients. Integr Cancer Ther. 2019; 18: 1534735419854134, doi: 10.1177/1534735419854134, indexed in Pubmed: 31170844. 
3. Wolf $C P$, Rachow T, Ernst T, et al. Complementary and alternative medicine (CAM) supplements in cancer outpatients: analyses of usage and of interaction risks with cancer treatment. J Cancer Res Clin Oncol. 2021 [Epub ahead of print], doi: 10.1007/s00432-021-03675-7, indexed in Pubmed: 34228225.

4. Johnson C, Aaronson N, Blazeby JM, et al. EORTC QUALITY OF LIFE GROUP Guidelines for Developing Questionnaire Modules [Internet]. 2011. https://www.eortc.org/app/uploads/sites/2/2018/02/guidelines_for_developing_questionnaire-_final.pdf (4.07.2021).

5. Tabachnick BG, Fidell LS. Using Multivariate Statistics Title: Using multivariate statistics. 5th ed. Allyn \& Bacon, Inc, Needham Heights, MA 2006.

6. Bosak M, Słowik A. Use of complementary and alternative medicine among adults with epilepsy in a university epilepsy clinic in Poland. Epilepsy Behav. 2019; 98(Pt A): 40-44, doi: 10.1016/j.yebeh.2019.06.004, indexed in Pubmed: 31299531

7. Toivonen Kl, Tamagawa R, Speca M, et al. Open to Exploration? Association of Personality Factors With Complementary Therapy Use After Breast Cancer Treatment. Integr Cancer Ther. 2018; 17(3): 785-792, doi: 10.1177/1534735417753539, indexed in Pubmed: 29361852.

8. Berretta $M$, Della Pepa C, Tralongo P, et al. Use of Complementary and Alternative Medicine (CAM) in cancer patients: An Italian multicenter survey. Oncotarget. 2017; 8(15): 24401-24414, doi: 10.18632/oncotarget.14224, indexed in Pubmed: 28212560.

9. Wode K, Henriksson R, Sharp L, et al. Cancer patients' use of complementary and alternative medicine in Sweden: a cross-sectional study. BMC Complement Altern Med. 2019; 19(1): 62, doi: 10.1186/s12906019-2452-5, indexed in Pubmed: 30866916.

10. Snyder J, Zenone M, Caulfield T. Crowdfunding for complementary and alternative medicine: What are cancer patients seeking? PLoS One. 2020; 15(11): e0242048, doi: 10.1371/journal.pone.0242048, indexed in Pubmed: 33216790.

11. Holmes MM, Bishop FL, Calman L.,/l just googled and read everything": Exploring breast cancer survivors' use of the internet to find information on complementary medicine. Complement Ther Med. 2017; 33: 78-84, doi: 10.1016/j.ctim.2017.06.007, indexed in Pubmed: 28735830.

12. Scott JA, Kearney N, Hummerston S, et al. Use of complementary and alternative medicine in patients with cancer: a UK survey. Eur J Oncol Nurs. 2005; 9(2): 131-137, doi: 10.1016/j.ejon.2005.03.012, indexed in Pubmed: 15944106.

13. Huebner J, Prott FJ, Micke O, et al. PRIO (Working Group Prevention and Integrative Oncology - German Cancer Society). Online survey of cancer patients on complementary and alternative medicine. Oncol Res Treat. 2014; 37(6): 304-308, doi: 10.1159/000362616, indexed in Pubmed: 24903760.

14. Molassiotis A, Potrata B, Cheng KKF. A systematic review of the effectiveness of Chinese herbal medication in symptom management and improvement of quality of life in adult cancer patients. Complement Ther Med. 2009; 17(2): 92-120, doi: 10.1016/j.ctim.2008.11.002, indexed in Pubmed: 19185267.

15. Asiimwe JB, Nagendrappa PB, Atukunda EC, et al. Prevalence of the Use of Herbal Medicines among Patients with Cancer: A Systematic Review and Meta-Analysis. Evid Based Complement Alternat Med. 2021; 2021: 9963038, doi: 10.1155/2021/9963038, indexed in Pubmed: 34055029.

16. Eliott JA, Kealey CP, Olver IN. (Using) complementary and alternative medicine: the perceptions of palliative patients with cancer. J Palliat Med. 2008; 11(1): 58-67, doi: 10.1089/jpm.2007.0102, indexed in Pubmed: 18370894.
17. Krakowiak P. Gaps in end-of-life care and lack of support for family carers in Poland and Central Eastern Europe. Palliat Care Soc Pract. 2020 14: 2632352420958001 , doi: $10.1177 / 2632352420958001$, indexed in Pubmed: 33063014.

18. Anderson JG, Taylor AG. Use of complementary therapies for cancer symptom management: results of the 2007 National Health Interview Survey. J Altern Complement Med. 2012; 18(3): 235-241, doi: 10.1089/ acm.2011.0022, indexed in Pubmed: 22420737.

19. Karadag E, Yüksel S. Complementary, Traditional and Spiritual Practices Used by Cancer Patients in Turkey When Coping with Pain: An Exploratory Case Study. J Relig Health. 2021; 60(4): 2784]2798, doi: 10.1007/ s10943-021-01276-9, indexed in Pubmed: 33990887.

20. Abuelgasim KA, Alsharhan Y, Alenzi T, et al. The use of complementary and alternative medicine by patients with cancer: a cross-sectional survey in Saudi Arabia. BMC Complement Altern Med. 2018; 18(1): 88, doi: 10.1186/s12906-018-2150-8, indexed in Pubmed: 29530034.

21. Oh B, Butow P, Mullan B, et al. The use and perceived benefits resulting from the use of complementary and alternative medicine by cancer patients in Australia. Asia Pac J Clin Oncol. 2010; 6(4): 342-349, doi: 10.1111/j.1743-7563.2010.01329.x, indexed in Pubmed: 21114784.

22. Yun H, Sun L, Mao JJ. Growth of Integrative Medicine at Leading Cancer Centers Between 2009 and 2016: A Systematic Analysis of NCl-Designated Comprehensive Cancer Center Websites. J Natl Cancer Inst Monogr. 2017; 2017(52), doi: 10.1093/jncimonographs/Igx004, indexed in Pubmed: 29140485.

23. Sowada C, Sagan A, Kowalska-Bobkol, et al. Poland:Health System Review. Health Syst Transit. 2019; 21(1): 1-234, indexed in Pubmed: 31333192.

24. Johnson SB, Park HS, Gross CP, et al. Complementary Medicine, Refusal of Conventional Cancer Therapy, and Survival Among Patients With Curable Cancers. JAMA Oncol. 2018; 4(10): 1375-1381, doi: 10.1001/ jamaoncol.2018.2487, indexed in Pubmed: 30027204.

25. Neuhouser ML, Smith AW, George SM, et al. Use of complementary and alternative medicine and breast cancer survival in the Health, Eating, Activity, and Lifestyle Study. Breast Cancer Res Treat. 2016; 160(3): 539546, doi: 10.1007/s10549-016-4010-x, indexed in Pubmed: 27766453.

26. Han E, Johnson N, DelaMelena T, et al. Alternative therapy used as primary treatment for breast cancer negatively impacts outcomes. Ann Surg Oncol. 2011; 18(4): 912-916, doi: 10.12s10434-010-1487-0, indexed in Pubmed: 21225354.

27. Campen CJ, Vogel WH, Shah PJ. Managing Drug Interactions in Cancer Therapy: A Guide for the Advanced Practitioner. J Adv Pract Oncol. 2017; 8(6): 609-620, indexed in Pubmed: 30310722.

28. Davis EL, Oh B, Butow PN, et al. Cancer patient disclosure and patient-doctor communication of complementary and alternative medicine use: a systematic review. Oncologist. 2012; 17(11): 1475-1481, doi: 10.1634/theoncologist.2012-0223, indexed in Pubmed: 22933591.

29. Foley $\mathrm{H}$, Steel A, Cramer $\mathrm{H}$, et al. Disclosure of complementary medicine use to medical providers: a systematic review and meta-analysis. Sci Rep. 2019; 9(1): 1573, doi: 10.1038/s41598-018-38279-8, indexed in Pubmed: 30733573.

30. Levy AG, Scherer AM, Zikmund-Fisher BJ, et al. Prevalence of and Factors Associated With Patient Nondisclosure of Medically Relevant Information to Clinicians. JAMA Netw Open. 2018; 1(7): e185293, doi: 10.1001/jamanetworkopen.2018.5293, indexed in Pubmed: 30646397.

31. Zasowska-Nowak A, Nowak PJ, Ciałkowska-Rysz A. High-Dose Vitamin C in Advanced-Stage Cancer Patients. Nutrients. 2021; 13(3), doi: 10.3390/ nu13030735, indexed in Pubmed: 33652579. 